\title{
Efficiency Improvement of Switched Reluctance Generator Using Optimization Techniques
}

\author{
Márcio R. C. Reis ${ }^{1,2}$, Wanderson R. H. Araújo ${ }^{1,2}$ and Wesley P. Calixto ${ }^{1,2}$
}

\begin{abstract}
This article introduces the switched reluctance machine operating as a generator. This kind of electrical machine delivers $\mathrm{CC}$ power at the output and the energy generated can be controlled through several variables. In this work, the switching angles of the machine's power converter are optimized using deterministic and heuristic techniques so that the output power is kept constant via PI controller while guaranteeing maximum efficiency value, even for different excitation values and mechanical power on the shaft.
\end{abstract}

Index Terms - Switched Reluctance Generator, optimization, control, genetic algorithm.

\section{INTRODUCTION}

$\mathrm{T}$ he constant search for clean energy at present creates the need for studies and tests related to energy sources such as solar and wind. Moreover, the climate change is a contemporary issue that requires a decrease in gas emissions. According to [1], existing research shows that in the last decades wind generation has become one of the topics discussed worldwide. This type of alternative source of energy has several advantages, such as: i) low environmental impact for installation of wind turbines. In this way, a small area is required for installed $\mathrm{kWh}$ compared to conventional power sources, ii) negligible greenhouse effect in comparison with other power sources, iii) low installation and maintenance costs, and iv) as far as the electronic advances, there are several ways to control the electric machine for better performance.

\section{SWITCHED RELUCTANCE GENERATOR}

Switched reluctance machines have a rotor with no winding. Single phase windings are concentrated in the stator. Both rotor and stator are made of ferromagnetic material and have projecting poles. Therefore, the machine is suitable for operating in a wide speed range. There are several configurations for switched reluctance machines. Fig. 1 shows the laminated package for reluctance machine with $6 \times 4$

${ }^{1}$ Experimental \& Technological Research and Study Group (NExT), Federal Institute of Goias (IFG), Goiania, Goias State, Brazil (e-mails: marciorcreis@gmail.com,_ wandersonrainer@gmail.com and wpcalixto@gmail.com).

${ }^{2}$ School of Electrical Engineering, Mechanical and Computer (EMC), Federal University of Goias (UFG). configuration [4].
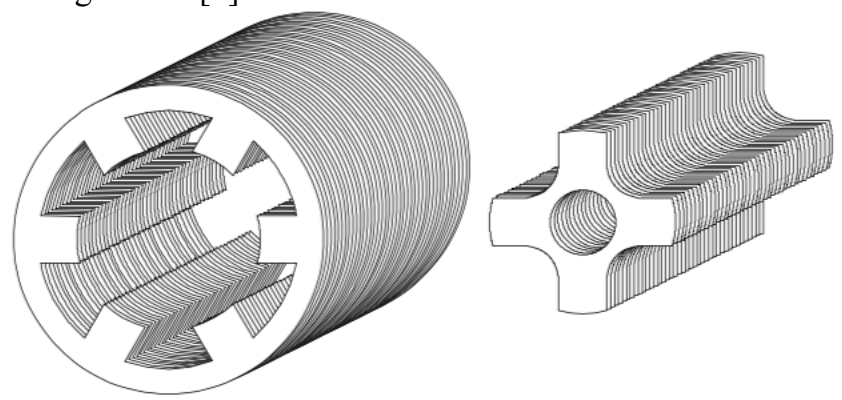

Fig. 1. Stator and rotor of a $6 \times 4$ SRM.

The phase windings are concentrated only in the stator. So for the SRG $6 \times 4$, there are three phases. This winding must be energized individually, and the energy application in each phase winding is provided by a power converter, as shown in Fig. 2 [4].

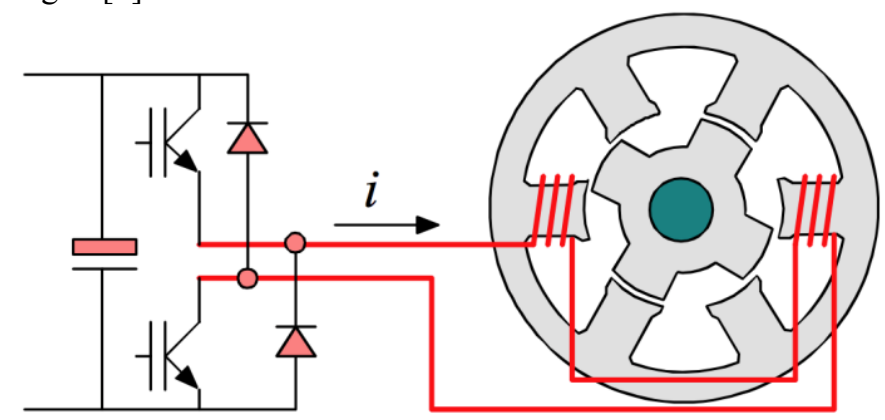

Fig. 2. Partial scheme for the Half Bridge Converter.

The production of torque occurs due to the tendency of alignment of the stator and rotor poles, when the respective phase is energized, and the position of reluctance is minimal for the established magnetic circuit and maximum inductance. On the other hand, if the mechanical energy is applied to the axis of the machine, the energized phase provides restorative torque resulting in additive counter-electromotive force, generating electric energy. The position of the rotor is required instantaneously, as the power converter energizes the winding phase at the correct time. The inductance profile for a phase of the SRG is shown in Fig. 3. 


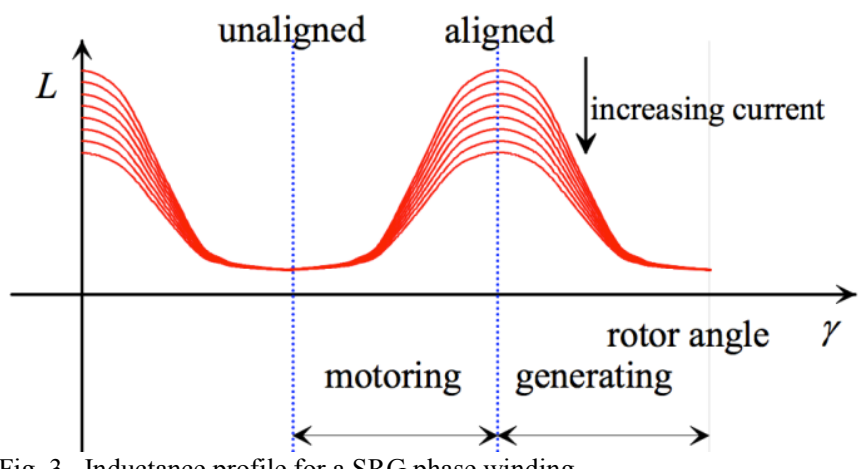

Fig. 3. Inductance profile for a SRG phase winding.

The machine shaft has coupled sensors that indicate the position of the rotor instantaneously so that the machine can be operated as a motor or generator. Considering the switched reluctance engine operating as a motor, the torque produced is given by (1) [5].

$$
\mathrm{T}=\frac{1}{2} \dot{b}^{2} \frac{\mathrm{dL}}{\mathrm{d} \theta}
$$

In (1), $i$ is the current applied to the machine phase winding, $L$ is the phase inductance and $\theta$ is the position of the rotor. Therefore, (1) indicates that the production of positive torque occurs when the phase winding is energized when inductance is increasing. If the primary motor supplies torque to the machine shaft, applying current to the winding of a phase during the decreasing inductance, it causes the restoring torque to be converted into electrical energy, which can be routed to the load. This condition makes the machine work as a generator. The SRG delivers CC power at the output, eliminating the need for one of two converters used in induction machines, $\mathrm{AC}-\mathrm{DC}$ and $\mathrm{DC}-\mathrm{AC}$, to connect to the power grid.

\section{Optimization TechniQues}

Optimization is the mathematical tool to be used in solving problems in which the most efficient solution among all the existing possibilities must be found. Such are called optimal or optimized solutions to the problem considered.

The optimization of the system by minimizing the function $f(x)$ is performed considering $\mathrm{x} \square \square^{\mathrm{n}}$. A basic optimization algorithm consists of determining the direction from each point obtained to take the next step. Since the goal is to minimize $f(x)$, it is reasonable for the function to decrease in the chosen direction [6] [7].

Optimization processes may be deterministic or heuristic in nature. In this work, both techniques are applied to the drive parameters of the switched reluctance generator in order to increase the efficiency of the machine, allowing the generation of energy, consuming less excitation power or requiring lower values of mechanical power in the generator axis.

Quasi-Newton methods are based on Newton's method to find the stationary point of a function, where the gradient is zero. Newton's method is deterministic and assumes that the function can be locally approximated as a quadratic in the region around the optimum, and uses the first and second derivatives to find the stationary point. In higher dimensions, Newton's method uses the gradient and the Hessian matrix of second derivatives of the function to be minimized.

Genetic algorithms are heuristic methods of random search inspired by evolutionary biology, such as: i) heredity, ii) mutation, iii) natural selection, and iv) recombination. They are implemented through a computer where the population of abstract solution representations is selected for improvements.

Another method used in this work is the hybrid method, in which the Quasi-Newton method is used in conjunction with the genetic algorithm. In this case, the genetic algorithm provides the Quasi-Newton method with its best individual. From it, the method will find the new individual, that is, the new, better adapted set of solutions [8][9].

Normally, hybridization is used to: i) improve the performance of existing techniques, ii) seek better solutions, and iii) divide complex problems by decomposing them into sub-problems where each algorithm / technique solves part of it.

\section{Methodology}

The use of the switched reluctance machine as a generator requires the application of current on the phase winding during the decreasing inductance. In addition, the initial instant of application of the current $\theta_{O N}$ and the instant when the phase winding is disconnected from the power source $\theta_{O F F}$ act directly on the output voltage generated and, as a result, on the output power. Other factors that interfere with the output power are the $V_{E X C}$ excitation voltage and the rotor speed $\omega$. Firstly, the mathematical model for the SRG $6 \times 4$ associated with power elements will be implemented in order to observe the operation of the machine as a generator. Fig. 4 illustrates the model to be used in simulation.

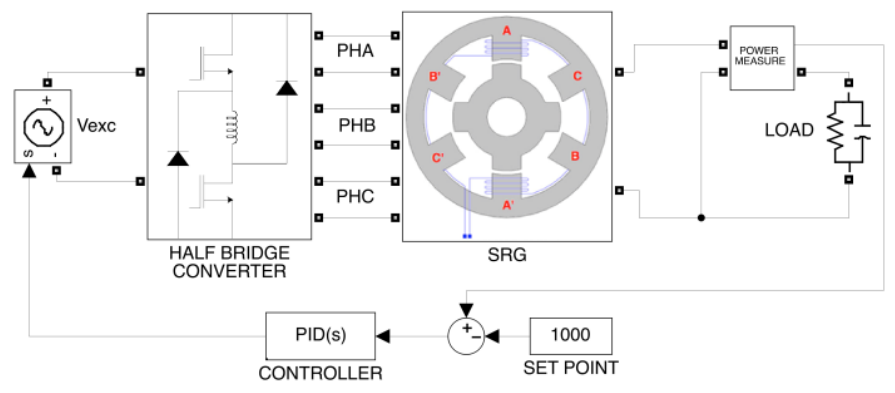

Fig. 4. Scheme for Matlab/Simulink simulation.

The firing angle of the semiconductor switches of the power converter, $\theta_{O N}$, was established at the maximum inductance (alignment position) for all three phases, and the off angle $\left(\theta_{O F F}\right)$ was set at $30^{\circ}$ after $\theta_{O N}$. Therefore, the triggering of the power converter switches has been set with a $30^{\circ}$ window for all the phases of the machine. This driving window is suitable for $6 \times 4$ machines as indicated in [6]. For all simulations, the load was set at $269 \Omega, 2.8 \mathrm{mF}$, and the machine parameters are shown in Table 1. 
TABLE I

SRG PARAMETERS

\begin{tabular}{ccc}
\hline \hline Symbol & Quantity & Value \\
& & \\
\hline $\mathrm{N}_{\mathrm{S}}$ & Stator poles & 6 \\
$\mathrm{~N}_{\mathrm{R}}$ & Rotor poles & 4 \\
$\mathrm{~L}_{\mathrm{MIN}}$ & Inductance for & $35 \mathrm{mH}$ \\
& unaligned position \\
$\mathrm{L}_{\mathrm{MAX}}$ & Inductance for aligned & $135 \mathrm{mH}$ \\
& position \\
$\mathrm{R}$ & Stator resistance \\
$\mathrm{B}$ & Friction & $3.25 \Omega$ \\
$\mathrm{J}$ & Inertia & $0.006 \mathrm{~kg} \cdot \mathrm{m}^{2} / \mathrm{s}$ \\
& & $0,04806 \mathrm{~kg} \cdot \mathrm{m}^{2}$ \\
\hline
\end{tabular}

The activation of the SRG with excitation voltage of $120 \mathrm{~V}$, driving angle of $30^{\circ}$ and speed of $1000 \mathrm{rpm}$ causes the machine to generate power of $1056.9 \mathrm{~W}$ with a yield of 0.8 , as shown in Fig. 5.
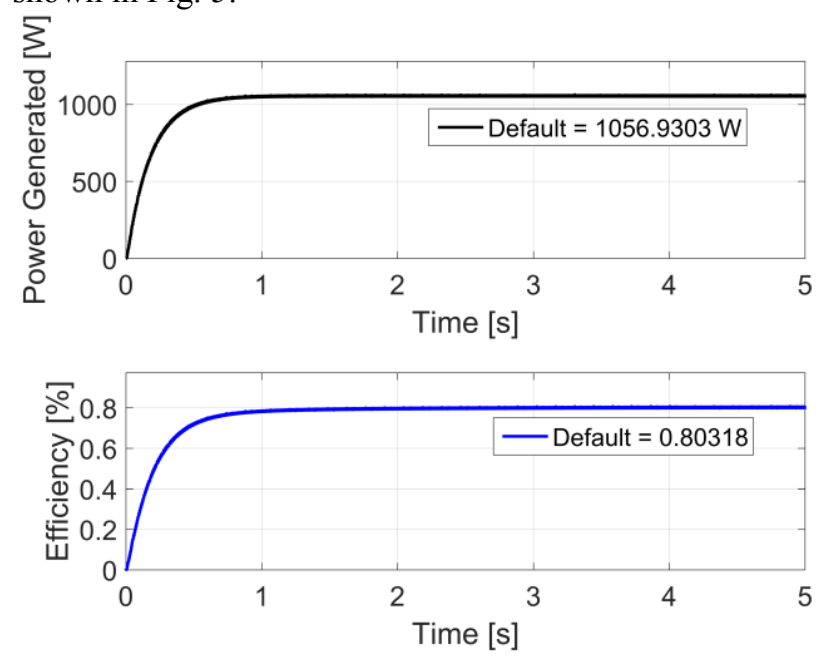

Fig. 5. SRG power and efficiency (open loop driving).

With these preliminary results, the objective of this study is to develop three methodologies: i) to apply the PI controller to the $V_{E X C}$ excitation voltage in order to guarantee fixed output power, $1000 \mathrm{~W}$ was chosen, ii) to apply the heuristic optimization method, Genetic Algorithm (GA), to find the best $\theta_{O N}$ and $\theta_{O F F}$ firing angles of each of the three phases, seeking to maximize the efficiency of the generator and iii) after establishing the optimized values of $\theta_{O N}$ and $\theta_{O F F}$, apply them to the drive of the half-bridge converter and use the hybrid optimization method (deterministic and heuristic) to optimize machine axis speed and power PI controller gains.

The objective is to find the best performance of the machine for a certain speed of rotation of the shaft, seeking lower values of excitation or mechanical power, in order to guarantee the generation of $1000 \mathrm{~W}$ of electric power with higher efficiency.

\section{RESULTS}

As part of the evaluation function, the optimization algorithms use the SRG yield given by (2).

$$
\mathrm{Fx}=1-\eta
$$

where $\eta$ is the SRG yield, given by (3)

$$
\eta=\frac{P_{O}}{P_{i}}
$$

where $\mathrm{P}_{\mathrm{O}}$ is the electric power in the load and $P_{i}$ is the sum of the excitation and mechanical powers of the SRG, both in watts.

The genetic algorithm was simulated with an initial population of 20 individuals, containing as seed the angles cited before with the $30^{\circ}$ window, which are: i) $\theta_{O N_{-} C}=30^{\circ}$ and $\theta_{O F F_{-} C}=60^{\circ}$, ii) $\theta_{O N_{-} B}=60^{\circ}$ and $\theta_{O F F_{-} B}=90^{\circ}$ and iii) $\theta_{O N_{-} A}=90^{\circ}$ and $\theta_{O F_{-} A}=120^{\circ}$. The mutation rate was $1 \%$ in the initial generation and $80 \%$ in the final generation. The crossing rate was $80 \%$ in the initial generation and $15 \%$ in the final generation. The selection method used was the tournament [7]. The maximum generation number (GMAX) was defined as 100 generations.

The non-uniform mutation operator and the dispersed crossover operator [7] were used. The PI controller was constructed in order to maintain fixed generation power through SRG excitation. The setpoint of the control system was 1000 W. Fig. 6 shows the evolution of the genetic algorithm, with an initial evaluation function of approximately $\mathrm{Fx}=16$ and after the convergence of the algorithm Fx $=$ 13.15 .

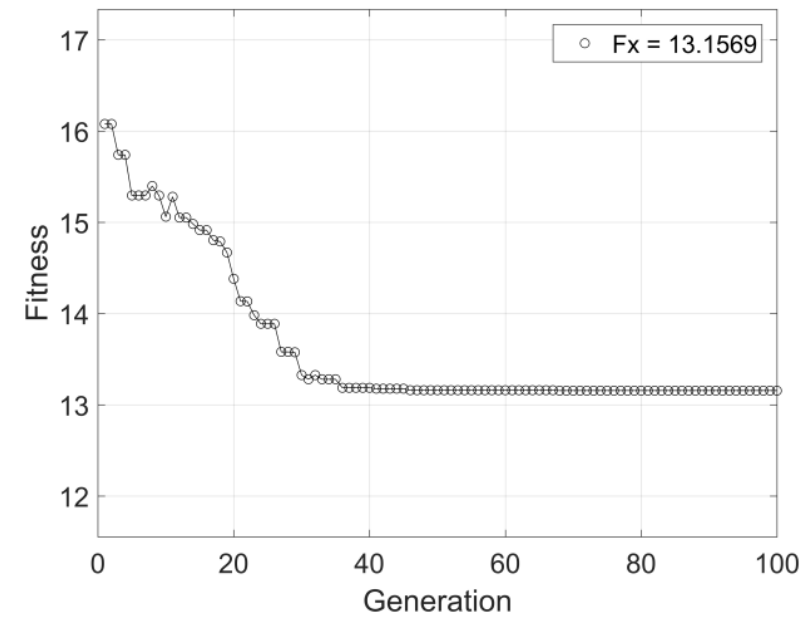

Fig. 6. Fitness evolution of the Genetic Algorithm.

The genetic algorithm converged in 40 generations and obtained an improvement of approximately $18 \%$ in the optimization process. The values of the angles found by the GA were: i) $\theta_{O N_{-} C}=29.22^{\circ}$ and $\theta_{O F F_{-} C}=54.46^{\circ}$, ii) $\theta_{O N_{-} B}=$ $58.01^{\circ}$ and $\theta_{O F F_{-} B}=83.50^{\circ}$ and iii) $\theta_{O N_{-} A}=86.00^{\circ}$ and $\theta_{O F F_{-} A}=$ $113.62^{\circ}$. Fig. 7 shows the graph of SRG output power $\left(P_{O}\right)$ with the conventional angles and the optimized angles, both under the influence of the PI controller on the excitation. 


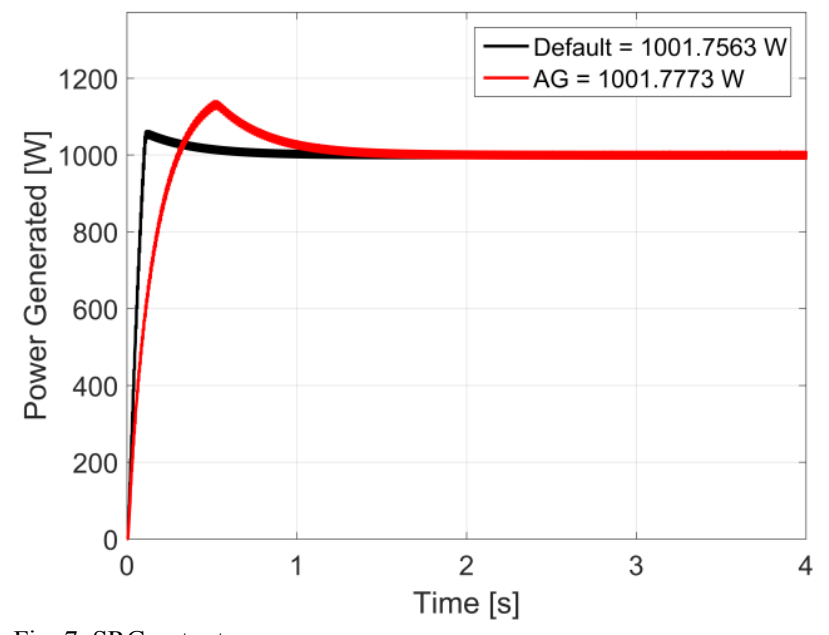

Fig. 7. SRG output power.

Fig. 7 shows the generated power, which reaches the system set point at approximately $1000 \mathrm{~W}$, using the PI controller. There was a slight change in the transient between the two tests, because the PI controller, as it is a linear system, behaves differently when the switching angles change because of the non-linearity inserted into the system. Fig. 8 illustrates the power supplied for SRG excitation.

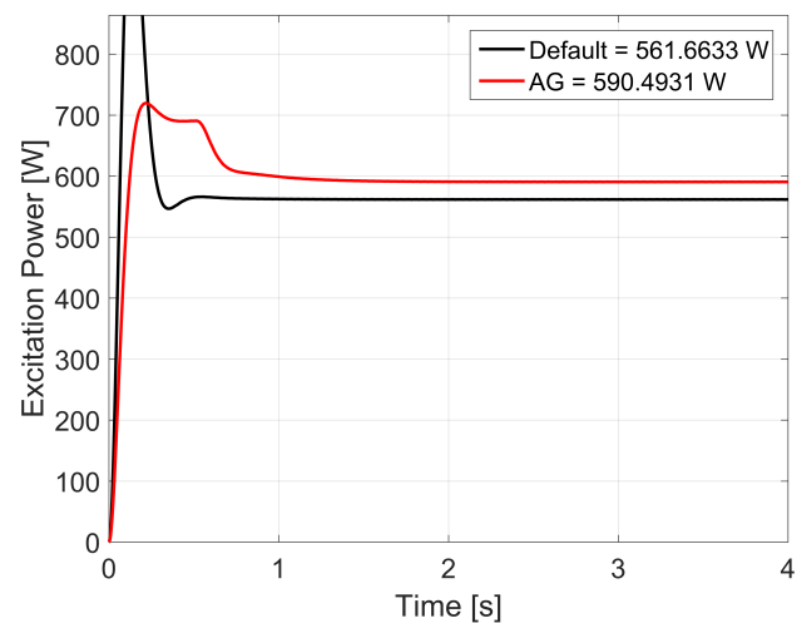

Fig. 8. SRG excitation power.

The power supplied for the SRG excitation is highest $(590.49 \mathrm{~W})$ when the angles found by the GA are used whereas the test with the standard angles indicates an excitation power of $561.49 \mathrm{~W}$. There was an increase in the electrical power supplied to SRG excitation of approximately $5 \%$ in the test with angles found through the GA. This would imply some worsening with respect to SRG yield, but some results will still be analyzed. Fig. 9 shows the mechanical power applied to the SRG axis for said tests.

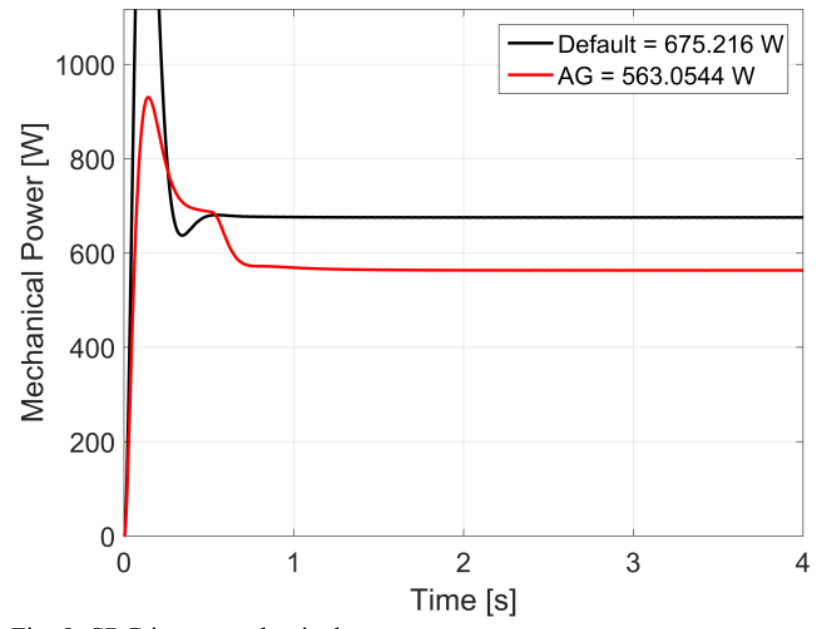

Fig. 9. SRG input mechanical power.

With the test using the activation angles of the phases found by the GA, the mechanical power supplied to the SRG is reduced by approximately $16.5 \%$. The mechanical power produced through the standard test was $675.21 \mathrm{~W}$ and through the GA, it was $563.05 \mathrm{~W}$. Accordingly, it can be emphasized that there was a small increase in the electric power provided by the voltage source responsible for SRG excitation and a greater decrease in the mechanical power supplied to the SRG. In this way, the process is validated, since the SRG produces the same electric power, with greater difference in the mechanical supply on the axis. This occurs because there is a PI controller in the excitation and the generation happens with an increase in the mechanical power, reducing the excitation power, as desired. The SRG yield for the standardized and optimized test is shown in Fig. 10.

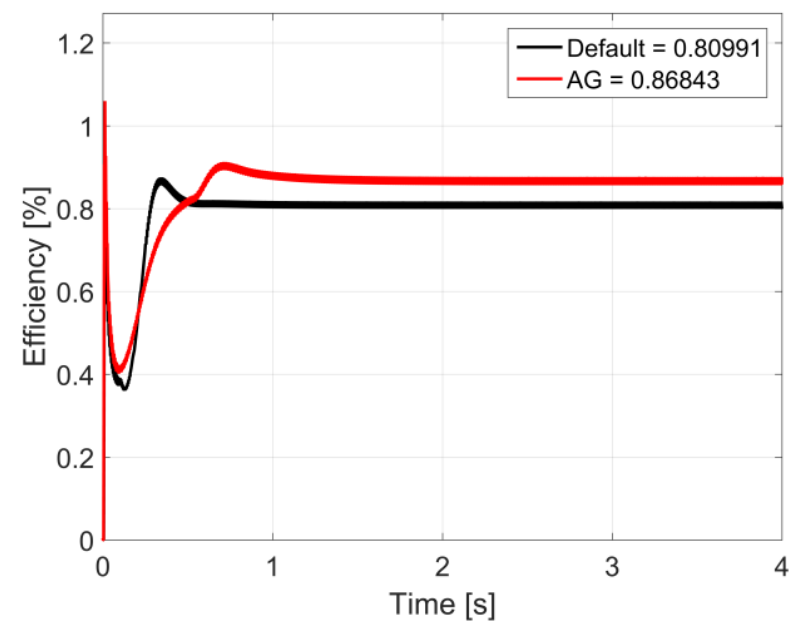

Fig. 10. SRG efficiency.

The yield of the SRG provided by the activation angles of the phases produced by the GA increases by approximately $9.5 \%$. The test performed with the standard angles and window fixed at $30^{\circ}$, has an output of 0.809 , and with the GA, 0.868 . It is a satisfactory improvement, considering that the SRG generates power of $1000 \mathrm{~W}$ with reduced mechanical power, with the only inconvenience that the power converter 
undergoes a slight overload. This causes the SRG to achieve a considerable reduction in energy consumption or to produce more power for the same supply.

The switching angles obtained by the optimization with the genetic algorithm were used as initial points for another optimization process, but now focusing on obtaining the angular velocity value in the generator axis that provides the best performance. However, with the speed change in the generator axis, it is necessary to obtain new parameters for the PI controller due to the fact that it is a linear control and does not allow the same performance for different speeds of rotation.

The optimization of the switching angles $\theta_{O N}$ and $\theta_{O F F}$ previously presented reduced the evaluation function $F x=16$ to $F x=13.15$. As the new optimization proposal takes into account the angular velocity and PI controller parameters, the $F x$ evaluation function was reformulated as described in (4).

$$
F x=[0,9 \llbracket(1-\eta)]+\left[0,1 e_{p}\right]
$$

This new evaluation function considers the yield of the SRG and the variable $e_{P}$, corresponding to the power error generated. This variable was considered for the adequate adjustment of the parameters $k p$ and $k i$ of the PI controller, but with less influence on $F x$ than the machine performance.

Thus, the six values obtained for the switching angles $\theta_{O N}$ and $\theta_{O F F}$ of the three machine phases using GA were used as starting points for the new evaluation function. Fig. 11 illustrates the evolution of this optimization starting from $F x=13.15$ to find the angular velocity value that maximizes the SRG efficiency associated with the controller which allows, at this new speed, the power of $1000 \mathrm{~W}$ generated in the load to be kept.

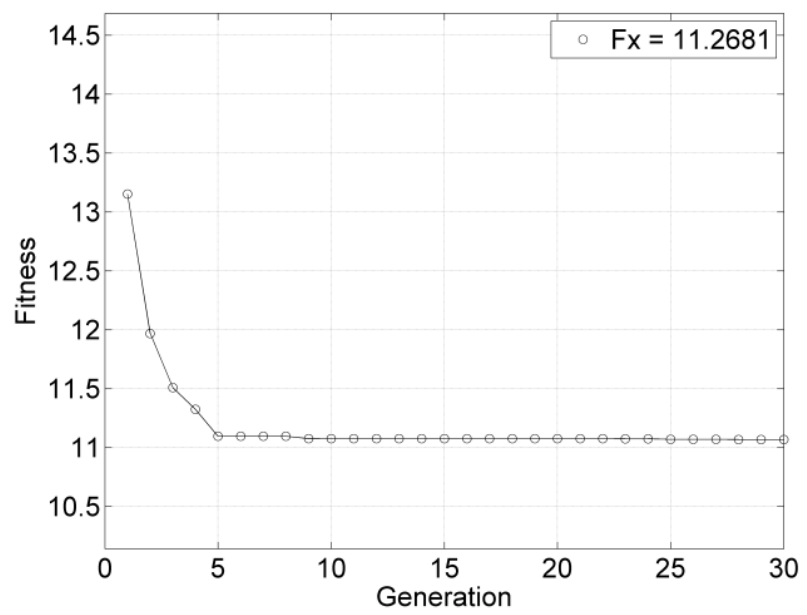

Fig. 11. GA fitness evolution (GA for $\omega, k p$ and $k i$ ).

It can be observed in Fig. 11 that $F x$ was minimized to 11.2681, so as to maximize yield and minimize error $e_{P}$ of the PI controller.

In order to improve the results obtained, this genetic algorithm was hybridized with the Quasi-Newton method. The values obtained in the optimization, illustrated by Fig. 11, were hybridized and $F x$ had its value reduced to 11.0683 , as shown in Fig. 12.

Fig. 12 shows that the initial value for $F x$ obtained in the previous optimization $(F x=11.2681)$, after some iterations, was applied to the hybrid GA causing a further reduction in the evaluation function $F x=11.0683$.

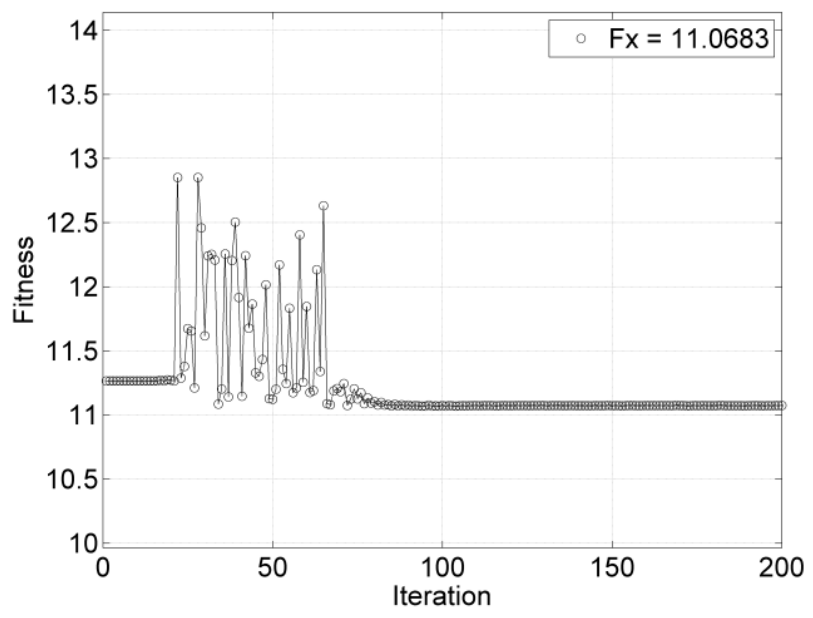

Fig. 12. Hybrid GA fitness evolution.

This reduction in $F x$ provided changes in the electric and mechanical variables of the SRG and guaranteed an improvement in the yield for the generation of the amount of $1000 \mathrm{~W}$ of electric power in the load.

Fig. 13 shows the power generated for the new speed value $(\omega=133.66 \mathrm{rad} / \mathrm{s})$ from the hybrid GA.

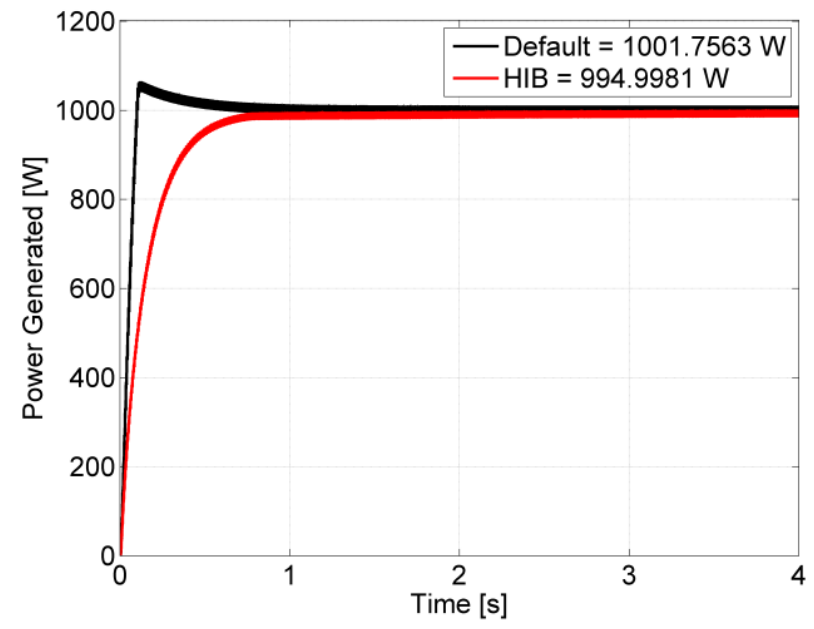

Fig. 13. SRG output power after hybrid GA optimization.

It is also possible to observe in Fig. 13 an electric output power of approximately $995 \mathrm{~W}$, causing a $0.5 \%$ error for the power PI controller.

Fig. 14 illustrates the excitation power of the SRG for generating the $995 \mathrm{~W}$, a result also obtained through the hybrid GA. 


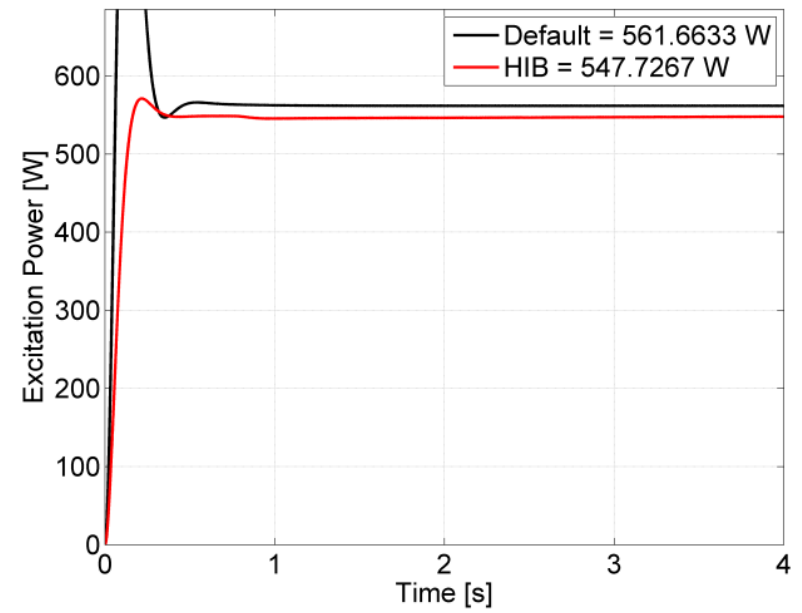

Fig. 14. SRG excitation power after hybrid GA optimization.

Among all the methods used in this article, the activation of the SRG with the values obtained $b$ through $y$ the hybrid GA is the one that required the least input electrical power (excitation) to generate the necessary output power. As shown in Fig. 14, a power of $547.73 \mathrm{~W}$ was required, whereas the activation with the conventional angles of $30^{\circ}$ of driving window, for an angular velocity of $100 \mathrm{rad} / \mathrm{s}$, required a power of $561.66 \mathrm{~W}$. Such values of excitation power allow variable $\eta_{E}$, which characterizes the electric efficiency of the generator, to be obtained, that is, the relation between the electric power generated at the output and the electric power of excitation at the input. Thus, $\eta_{E}$ represents the electric power balance in the machine, indicating how the device can generate power for a certain input power. Therefore, $\eta_{E}$ can be calculated as shown in (5).

$$
\eta_{\mathrm{E}}=\frac{\mathrm{P}_{\mathrm{O}}}{\mathrm{P}_{\mathrm{EXC}}}
$$

where $P_{E X C}$ represents the excitation power of the generator.

Fig. 15 shows the behavior of the mechanical power in the SRG axis for the power generation indicated in Fig. 13.

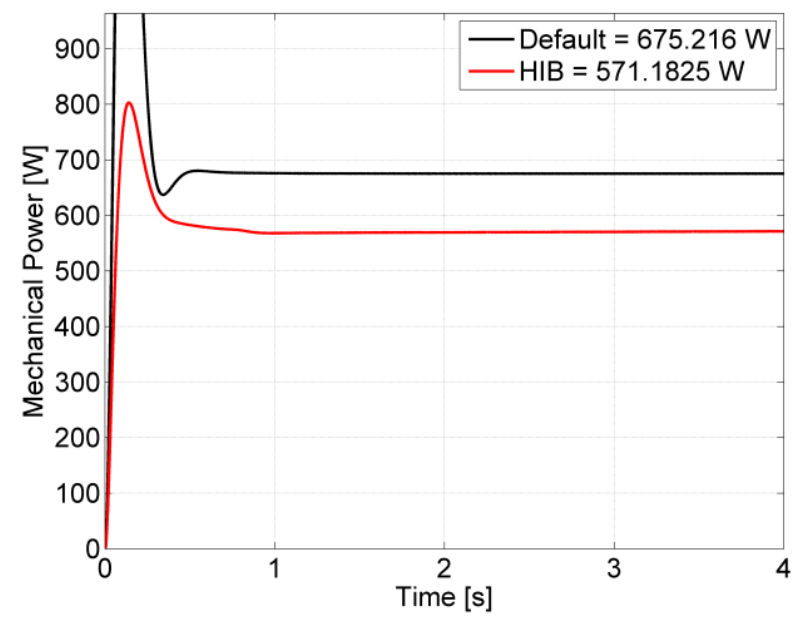

Fig. 15. SRG mechanical power after hybrid GA optimization.
Just as occurred with the excitation power, the mechanical input power was reduced from $675.22 \mathrm{~W}$ to $571.18 \mathrm{~W}$ using the hybrid GA. Both powers contribute positively to the efficiency of the generator if they are minimized, as indicated in (4).

Fig. 16 shows the efficiency of the generator with the drive performed with optimized parameters via the hybrid GA.

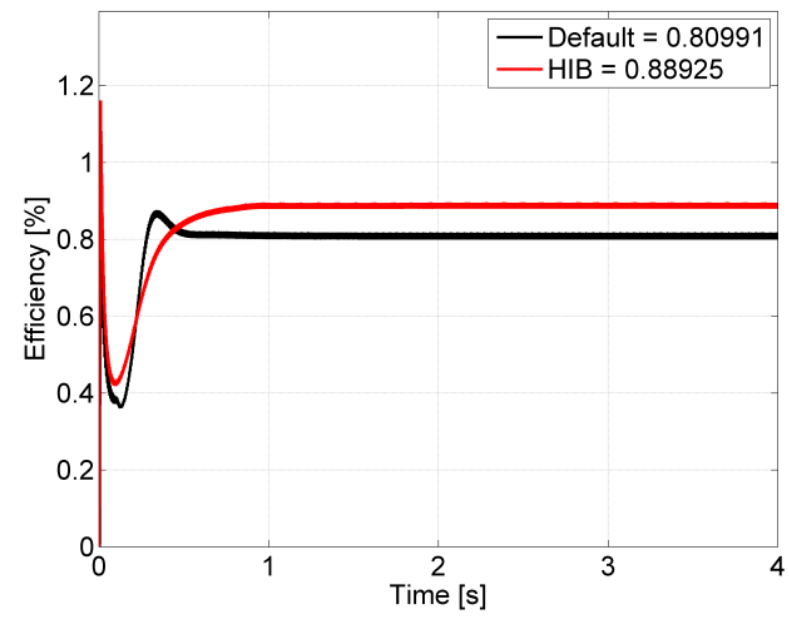

Fig. 16. SRG efficiency after hybrid GA optimization.

As expected, the reduction in mechanical and excitation powers caused an increase in the SRG yield, raising this variable from 0.81 to about 0.89 . The results indicate that the $\mathrm{GA}$, in spite of providing improved performance with the reduction of excitation power [9], if integrated with the QuasiNewton method, becoming a hybrid method, contributes positively with variables already optimized by the GA [10].

Table 2 and Table 3 show the results obtained quantitatively.

TABLE 2. SimULATION RESUlTS

\begin{tabular}{|c|c|c|c|}
\hline $\begin{array}{l}\text { Angles } \\
\left(\theta_{\mathrm{ON}} \text { e } \theta_{\mathrm{OFF}}\right)\end{array}$ & $\begin{array}{c}\text { Excitation } \\
\text { Power } \\
\left(\mathrm{P}_{\text {EXC }}\right) \\
\end{array}$ & $\begin{array}{c}\text { Mechanical } \\
\text { Power } \\
\left(\mathrm{P}_{\mathrm{MEC}}\right) \\
\end{array}$ & $\begin{array}{c}\text { Generated } \\
\text { Power } \\
\left(\mathrm{P}_{\mathrm{O}}\right) \\
\end{array}$ \\
\hline Default & $561.66 \mathrm{~W}$ & $675.20 \mathrm{~W}$ & $1001.75 \mathrm{~W}$ \\
\hline GA & $590.50 \mathrm{~W}$ & $563.05 \mathrm{~W}$ & $1001.78 \mathrm{~W}$ \\
\hline Hybrid GA & $547.73 \mathrm{~W}$ & $571.18 \mathrm{~W}$ & $995.00 \mathrm{~W}$ \\
\hline \multicolumn{4}{|c|}{ TABLE 3. SIMULATION RESULTS } \\
\hline $\begin{array}{c}\text { Angles } \\
\left(\theta_{\mathrm{ON}} \text { e } \theta_{\mathrm{OFF}}\right)\end{array}$ & $\begin{array}{l}\text { SRG Efficiency } \\
(\eta)\end{array}$ & $\begin{array}{c}\text { Electrical } \\
\text { Efficiency } \\
\left(\eta_{\mathrm{E}}\right)\end{array}$ & Rotor Speed \\
\hline Default & 0.809 & 1.783 & $100 \mathrm{rad} / \mathrm{s}$ \\
\hline GA & 0.868 & 1.696 & $100 \mathrm{rad} / \mathrm{s}$ \\
\hline Hybrid GA & 0.889 & 1.816 & $133.66 \mathrm{rad} / \mathrm{s}$ \\
\hline
\end{tabular}

Analyzing the results of Table 2 and Table 3, it is possible to verify that, although the mechanical power required for $1000 \mathrm{~W}$ generation with the SRG is higher in the hybrid GA than in the simple GA, the electric efficiency $\left(\eta_{E}\right)$ is higher for all the methodologies adopted. That is, it requires less excitation power to generate the same power when the appropriate speed is used for the generator and the optimized angles are used in the power converter. 


\section{CONCLUSIONS}

This article presents the results of simulation for three methodologies of optimization of parameters of switched reluctance generators. The generator is driven with the help of a PI controller for the excitation of the machine in order to maintain $1000 \mathrm{~W}$ of power generated over resistive load. The generator is activated with the help of a PI controller for the excitation of the machine so it keeps a generated power of $1000 \mathrm{~W}$ over resistive load. The switching angles of the power converter were optimized using the genetic algorithm and the results obtained from this optimization were used in a new process, in which the variables to be optimized were the rotor angular velocity and the parameters of the excitation PI controller. Therefore, a speed value was obtained at which the machine provides best performance. The hybrid genetic algorithm, coupled with the Quasi-Newton method, despite having provided results that indicate an increase of the mechanical power needed to generate $1000 \mathrm{~W}$ at the output of the generator, reduced the machine's excitation power the most, resulting in gain in the overall yield, approximately $10 \%$. These studies show how the use of SRG for power generation can be made more effective, especially in applications with a wide range of speed variation, considering the constructive aspects of the machine.

\section{REFERENCES}

[1] Z. Qixue. A small single-phase switched reluctance generator for wind power generation. ICEMS 2001 proceeding of the fifth international conference electrical machines and systems. 2001. VOL 2. Aug 2001 pages 1003-1006.

[2] M. Nassereddine, J. Rizk, and M. Nagrial. Switched Reluctance Generator for Wind Power Applications. World Academy of Science, Engineering and Technology International Journal of Mechanical, Aerospace, Industrial, Mechatronic and Manufacturing Engineering Vol:2, No:5, 2008.

[3] K. Bouchoucha, H. Yahia, M. N. Mansouri. Particle Swarm Optimization of Switched Reluctance Generator based Distributed Wind Generation. Journal of Multidisciplinary Engineering Science and Technology (JMEST) ISSN: 3159-0040 Vol. 1 Issue 4, November 2014.

[4] Juha Pyrhonen. Electrical Drives. LUT (Lappeenranta University of Technology), Department of Electrical Engineering. Finland.

[5] Araujo, Wandeson R. H.; Ganzaroli, Cleber A. ; Calixto, Wesley. P. ; Alves, Aylton J. ; Viajante, Ghunter P. ; Reis, Marcio R. C. ; Silveira, Augusto F. V. Firing angles optimization for Switched Reluctance Generator using Genetic Algorithms. In: 2013 13th International Conference on Environment and Electrical Engineering (EEEIC), 2013, Wroclaw. 2013 13th International Conference on Environment and Electrical Engineering (EEEIC), 2013. p. 217.

[6] T. J. E. Miller. Switched Reluctance Motors and Their Control. Oxford, U.K.: Clarendon, 1993.

[7] Michalewicz, Zbigniew. genetic algorithms + data structures $=$ evolution programs. Springer, (1996).

[8] Calixto, Wesley Pacheco, et al. "parameters estimation of a horizontal multilayer soil using genetic algorithm". Power Delivery, IEEE Transactions on 25.3 (2010): 1250-1257.

[9] Reis, M. R. C. ; CALIXTO, W. P. ; Araújo, Wanderson Rainer Hilário de; Alves, A. J. ; Domingos, J. L. . Switched reluctance generator efficiency improvement for wind energy applications. In: 16th IEEE International Conference on Environment and Electrical Engineering, 2016, Florença. 16th IEEE International Conference on Environment and Electrical Engineering, 2016.

[10] Reis. M. R. C. ; Márcio Rodrigues da Cunha reis. Análise Comparativa de Métodos de Otimização Aplicados à Sintonia do Controlador PI.

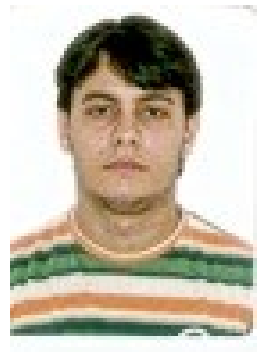

Márcio Rodrigues da Cunha Reis has graduation at Engenharia Elétrica by Pontifícia Universidade Católica de Goiás (2011) and master's at Engenharia Elétrica e de Computação by Universidade Federal de Goiás (2014) . Currently is of Instituto Federal de Educação, Ciência e Tecnologia de Goiás e of Companhia Energética de Goiás. Has experience in the area of Electric Engineering, with emphasis on Sistemas Microprocessados.

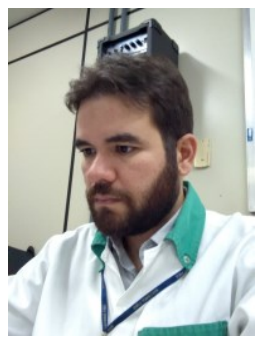

Wanderson Rainer Hilário de Araújo is graduate at Engenharia Elétrica from Universidade Católica de Goiás (2003), graduate at Redes de Comunicação from Centro Federal de Educação Tecnológica de Goiás (2002) and master's at Electric Engineering from Universidade Federal de Goiás (2006). Has experience in Electric Engineering, focusing on Transmission of the Electric Energy, Distribution of the Electric Energy, acting on the following subjects: engenharia elétrica, acionamento, relutância and motor.

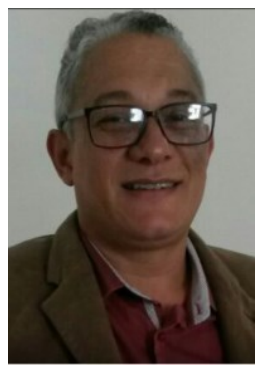

Wesley Pacheco Calixto is professor in Physics , M.Sc. in Electrical and Computer Engineering from the Federal University of Goias. Completed his PhD in Electrical Engineering from the Federal University of Uberlandia with part of this time at the University of Coimbra, Portugal. Currently he is Professor/Researcher at the Experimental \& Technological Research and Study Group (NExT/IFG).. 